Research Article

\title{
Mechanical Performance of Concrete Made with Recycled Aggregates from Concrete Pavements
}

\author{
Yancong Zhang $\mathbb{D}^{1,2}$ Lingling Gao, ${ }^{3}$ and Wei Bian ${ }^{2}$ \\ ${ }^{1}$ College of Highway, Chang'an University, Xi'an 710064, China \\ ${ }^{2}$ Key Lab of Highway Construction \& Maintenance Technology in Loess Region, \\ Shanxi Provincial Transportation Technology R\&D Co. Ltd., Taiyuan 030032, China \\ ${ }^{3}$ Department of Engineering Management, Shanxi Conservancy Technical Institute, Taiyuan 030027, China \\ Correspondence should be addressed to Yancong Zhang; yc_zhang@chd.edu.cn
}

Received 27 June 2020; Revised 28 August 2020; Accepted 29 August 2020; Published 15 September 2020

Academic Editor: Robert Černý

Copyright (c) 2020 Yancong Zhang et al. This is an open access article distributed under the Creative Commons Attribution License, which permits unrestricted use, distribution, and reproduction in any medium, provided the original work is properly cited.

\begin{abstract}
This research aims at analysing the mechanical performance of concrete with recycled aggregates from concrete pavements. First, the characteristics of various natural and recycled aggregates used in the concrete were thoroughly analysed. The composition of the recycled aggregates was determined and several physical and chemical tests of the aggregates were performed. In order to evaluate the mechanical performance of recycled concrete, cube compressive strength and flexural tensile strength tests were performed. The effect of recycled aggregates on the strength of recycled concrete is related to the strength of recycled aggregates, the strength of natural aggregates, and the strength of old concrete. The strength of recycled concrete decreases with increasing water-cement ratio. However, due to the water absorption of the recycled aggregate, it has a certain inhibitory effect on the strength reduction. As the replacement rate of recycled aggregates increases, the optimal sand ratio decreases. The sand ratio is controlled between $32 \%$ and $38 \%$, which is ideal for recycled concrete. With the increase of fly ash content, the $7 \mathrm{~d}$ strength of recycled concrete has decreased to some extent, but the $28 \mathrm{~d}$ strength has been slightly improved. In addition, for compressive strength and flexural tensile strength, the optimal content of fly ash is different.
\end{abstract}

\section{Introduction}

In several developed countries such as Europe and the United States, the use of recycled aggregates for concrete has been for many years [1]. According to De Vries, the application of recycled aggregate in construction engineering has become a priority in many places around the world [2]. 78000 tons of recycled aggregates were used in the Netherlands in 1994. According to Collins, $10 \%$ of the total aggregates used in the United Kingdom are recycled aggregates. Meanwhile, Germany has been aiming a target of $40 \%$ recycling rate of its building and demolition waste since 1991 [3]. In the United States, nearly 100 highway paving projects by the mid-1990s had incorporated recycled aggregates in concrete for pavements.
In China, the consumption of cement is 13.71 billion tons in 2018, a year-on-year increase of $6.6 \%$. It is estimated that approximately 246 million tons of waste concrete are currently produced annually in the mainland of China $[4,5]$. The difficulties of a developing scarcity of virgin aggregate together with disposing of the concrete waste have prompted an urge to recycle waste concrete as aggregates in fresh concrete. In recent years, many Chinese investigators have engaged in the studying of recycled aggregates and nearly all aspects of mechanical property and structural performance have been covered.

Recycled aggregates from concrete pavements are concrete fragments obtained by recycled concrete pavement slabs after being crushed, washed, and classified [6-8]. Many scholars have carried out research on the mechanical 
properties of concrete made with recycled aggregates from concrete pavements and have achieved many interesting results. Recycled aggregates contain certain amount of cement mortar which is characteristic of low density, big porosity, high water absorption, rough surface, and many microcracks, thus resulting in the poor property of pavement mixture containing recycled aggregates [9-12]. The majority of research conducted on recycled aggregate concrete focuses on using recycled coarse aggregates as a granular material [13-15] and as cement stabilised materials in base and subbase layers [16-18]. In contrast, there are few studies on the replacement of coarse and fine aggregate at the same time to prepare recycled concrete.

Strength is the most important mechanical indices of recycled concrete. The strength of recycled concrete is usually defined as the ability to resist external damage, sometimes the damage is equivalent to the occurrence of cracks [19]. For recycled aggregate concrete, the performance of aggregate is one of the most important factors affecting the strength of recycled aggregate concrete due to the addition of recycled aggregate [20]. Aggregate has two effects on the strength of concrete. One is the influence of the strength of the aggregate itself; the other is the influence on the interface bonding performance. In ordinary concrete, the elastic modulus of aggregate and cement mortar differ greatly. Due to cement hydration, temperature change, and load, the deformation of the two is inconsistent, resulting in interface cracks, which become the weakest link in concrete strength. In recycled concrete, the surface of recycled aggregate is covered with cement mortar. The difference between the elastic modulus of recycled aggregate and cement mortar is small, and the interface between the two is strengthened. At the same time, the recycled aggregate is highly hydrophilic and can be quickly wetted by water. Many microcracks on the surface of the recycled aggregates will suck in new cement particles, making the hydration of the contact area more complete and then forming a dense interface structure.

Based on the previous research, this study replaces coarse and fine aggregate at the same time and compares the effects of recycled aggregate replacement rate, water-cement ratio, sand ratio, and fly ash content on the mechanical properties of recycled aggregate concrete, such as cube compressive strength and flexural tensile strength.

\section{Test Materials and Methods}

2.1. Test Materials. Waste concrete was directly collected from concrete pavement demolishing spot, and sorting was conducted. After secondary crushing using an impact crusher or an E-crusher aggregate crushing plant, the concrete was graded into three types of fine and coarse recycled aggregates with sizes of $10-30 \mathrm{~mm}, 5-10 \mathrm{~mm}$, and smaller than $5 \mathrm{~mm}$. The natural aggregate used in the test was granite, including $10-30 \mathrm{~mm}, 5-10 \mathrm{~mm}$, and smaller than $5 \mathrm{~mm}$. The test results of physical and mechanical indices of aggregates are shown in Tables 1 and 2 according to Test methods of Aggregate for Highway Engineering (JTG E42-2005) of China.
The recycled aggregate behaved higher crushed value than the granite aggregate, but it still met the requirement of not higher than 30\% in Technical Specifications for Construction of Highway Base of China. Recycled aggregate had higher needle-chip particle content than the granite aggregate. Its water absorption was far higher than that of granite aggregate.

The recycled fine aggregate showed higher sand equivalent and angularity than granite fine aggregate, but was sturdy. These indicate that recycled aggregate meets the requirements of pavement slab of highway in China.

The solid content of the water reducing agent used in the test is $23 \%$, and the $\mathrm{pH}$ value is 6.8 . The water reduction rate is $21 \%$, and the chloride ion content is $0 \%$.

2.2. Mix Proportion of Concrete. Coarse aggregate was the basis of forming the skeleton of cement concrete, while fine aggregate mainly fills in the internal void of the skeleton. The aggregate gradation had a direct impact on the performance of cement concrete [21]. The flexural strength of concrete that was made of continuous graded gravel was higher than that of discontinuous gradation.

In the test, eleven groups of continuous gradations' aggregates were prepared by replacing granite with $0 \%, 10 \%$, $20 \%, 30 \%, 40 \%, 50 \%, 60 \%, 70 \%, 80 \%, 90 \%$, and $100 \%$ of recycled aggregate. In each grading, fine and coarse aggregate were replaced in the same proportion. The eleven continuous gradations were shown in Figure 1. In this figure, curve "RA $=0 \%$ " is the gradation curve of natural aggregate, and curve " $\mathrm{RA}=100 \%$ " is the gradation curve of recycled aggregate.

The mechanical properties of several kinds of recycled aggregates concrete were investigated to understand the change rule. Firstly, recycled aggregate concrete was studied with $0.10,0.20,0.30,0.40,0.50,0.60,0.70,0.80,0.90$, and 1.0 aggregates replacement rate. Then, the concrete was studied with $0.29,0.31,0.33,0.35$, and 0.37 water-cement ratio. For sand ratio, the doping amount mainly included $0.35,0.37$, $0.39,0.41$, and 0.43 . For fly ash, the doping amount mainly included $0,0.10,0.20,0.30$, and 0.40 . The mix proportion of concrete with recycled aggregates is shown in Table 3.

It can be seen from Tables 1 and 2 that the water absorption rate of recycled aggregate is significantly higher than that of natural aggregate. To ensure that the slump of recycled concrete and natural aggregate concrete is similar, the recycled coarse and fine aggregate must be prewetted before mixing. Referring to the existing results [22], the recycled aggregates are prewetted in this test, and the water consumption is $70 \%$ of the water absorption rate of the recycled aggregates. The water consumption shown in Table 3 does not include prewetting water.

2.3. The Preparation and Test Methods of Concrete. The mixing of recycled aggregates concrete was carried out according to the test methods of cement and concrete for highway engineering (JTG E30-2005). The slump of concrete should be measured and predicted to ensure the mixing quality of recycled aggregate concrete. The vibration table 
TABle 1: Physical and mechanical performance of coarse aggregates.

\begin{tabular}{|c|c|c|c|c|c|c|c|}
\hline \multirow[t]{2}{*}{ Aggregate types } & \multirow[t]{2}{*}{ Crushed value (\%) } & \multicolumn{2}{|c|}{ Apparent relative density } & \multicolumn{2}{|c|}{ Water absorption (\%) } & \multicolumn{2}{|c|}{$\begin{array}{c}\text { Needle-chip particle } \\
\text { content }(\%)\end{array}$} \\
\hline & & $5-10 \mathrm{~mm}$ & $10-30 \mathrm{~mm}$ & $5-10 \mathrm{~mm}$ & $10-30 \mathrm{~mm}$ & $5-10 \mathrm{~mm}$ & $10-30 \mathrm{~mm}$ \\
\hline Natural & 18.4 & 2.650 & 2.693 & 1.25 & 1.18 & 2.4 & 3.6 \\
\hline Recycled & 24.5 & 2.627 & 2.671 & 4.88 & 4.29 & 4.2 & 6.6 \\
\hline
\end{tabular}

TABle 2: Physical and mechanical performance of fine aggregates.

\begin{tabular}{lccccc}
\hline Aggregate types & Apparent relative density & Sand equivalent (\%) & Water absorption rate (\%) & Sturdiness (\%) & Angularity (s) \\
\hline Natural & 2.741 & 60.5 & 1.52 & 7.4 & 46 \\
Recycled & 2.627 & 79.8 & 5.04 & 6.2 & 47 \\
\hline
\end{tabular}

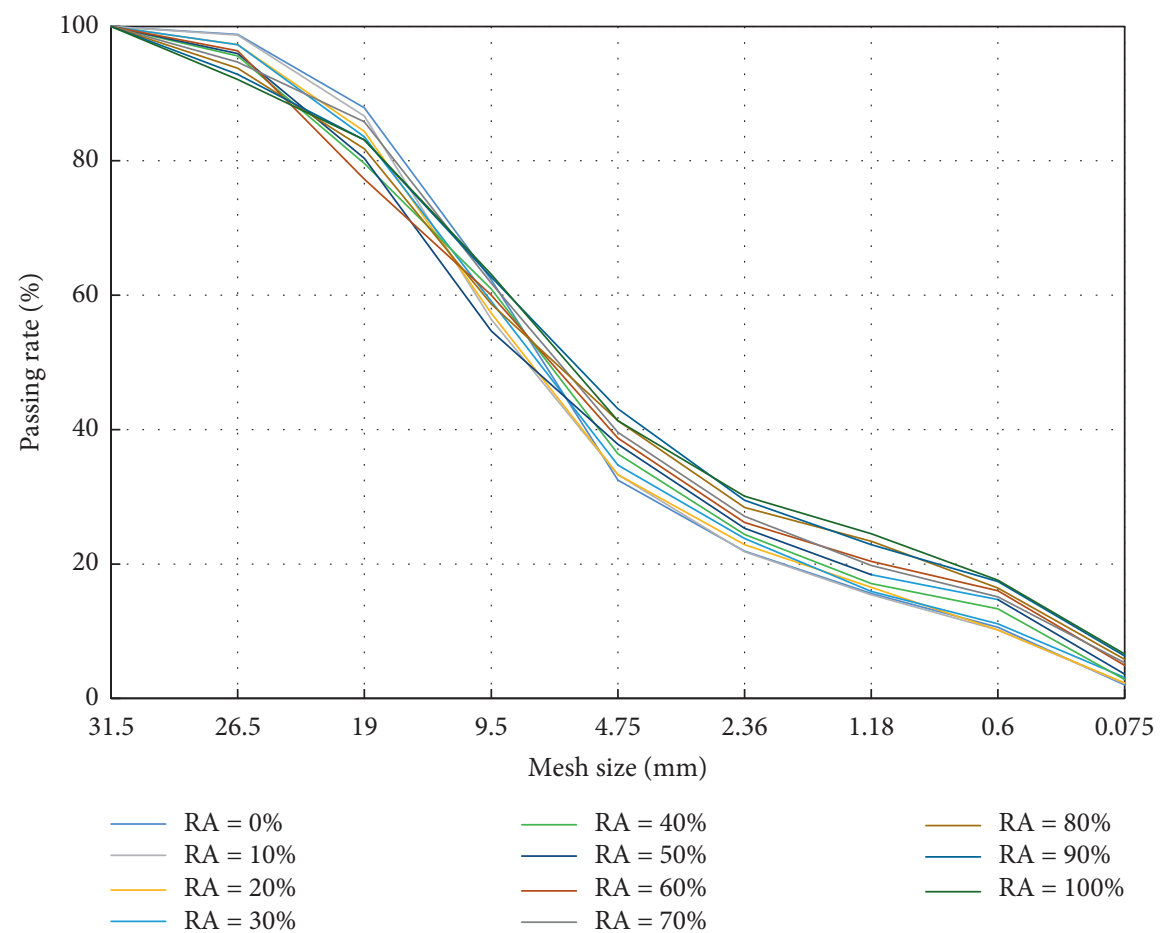

Figure 1: Grading curve.

should be used to vibrate, until the floating slurry appears on the concrete surface. Plastic film was used to seal the sample surface to reduce the moisture loss after forming. After $24 \mathrm{~h}$, demould and store with a constant temperature of $20^{\circ} \mathrm{C}$ and humidity of $95 \%$.

The mixing of recycled aggregate concrete was carried out according to the specification "test methods of cement and concrete for highway engineering (JTG E30-2005)".

The test methods of mechanical properties such as compressive strength and flexural tensile strength of recycled aggregate concrete were carried out according to the specification JTG E30-2005.

\section{Results and Discussion}

3.1. Effect of Replacement Rate of Recycled Aggregate on Strength. When the water-cement ratio is the same, the apparent density of recycled aggregate concrete decreases continuously with the increase of recycled aggregate replacement, as shown in Figure 2. As the replacement rate of recycled aggregates continues to increase, the apparent density of concrete continues to decrease. When the substitution rate is between $30 \%$ and $70 \%$, the decrease in apparent density is larger, as shown in the curve inside the ellipse. This is due to the fact that a certain amount of mortar is attached to the surface of the recycled aggregate, resulting in a lower density of recycled aggregate than the natural aggregate. Therefore, as the replacement rate of recycled aggregate increases, the apparent density of recycled aggregate concrete decreases regularly. From another perspective, the apparent density of recycled concrete is lower than that of conventional concrete, which is beneficial to reduce the weight of concrete structure and increase the span of the structure. 
TABLE 3: The mix proportion of concrete.

\begin{tabular}{|c|c|c|c|c|c|c|c|c|c|}
\hline \multirow{3}{*}{ No. } & \multirow{3}{*}{ Water-cement ratio (\%) } & \multicolumn{8}{|c|}{ Content $\left(\mathrm{kg} \cdot \mathrm{m}^{3}\right)$} \\
\hline & & \multirow{2}{*}{ Water } & \multirow{2}{*}{ Cement } & \multirow{2}{*}{ Fly ash } & \multicolumn{2}{|c|}{ Fine aggregates } & \multicolumn{2}{|c|}{ Coarse aggregates } & \multirow{2}{*}{ Water-reducing agent } \\
\hline & & & & & Natural & Recycled & Natural & Recycled & \\
\hline RA0 & 0.33 & 122.77 & 370.00 & 0 & 763.00 & 0.00 & 1193.00 & 0.00 & 1.11 \\
\hline RA10 & 0.33 & 122.77 & 370.00 & 0 & 686.70 & 76.30 & 1073.70 & 119.30 & 1.11 \\
\hline RA20 & 0.33 & 122.77 & 370.00 & 0 & 610.40 & 152.60 & 954.40 & 238.60 & 1.11 \\
\hline RA30 & 0.33 & 122.77 & 370.00 & $\mathbf{0}$ & 534.10 & 228.90 & 835.10 & 357.90 & 1.11 \\
\hline RA40 & 0.33 & 122.77 & 370.00 & 0 & 457.80 & 305.20 & 715.80 & 477.20 & 1.11 \\
\hline RA50 & 0.33 & 122.77 & 370.00 & 0 & 381.50 & 381.50 & 596.50 & 596.50 & 1.11 \\
\hline RA60 & 0.33 & 122.77 & 370.00 & 0 & 305.20 & 457.80 & 477.20 & 715.80 & 1.11 \\
\hline RA70 & 0.33 & 122.77 & 370.00 & 0 & 228.90 & 534.10 & 357.90 & 835.10 & 1.11 \\
\hline RA80 & 0.33 & 122.77 & 370.00 & 0 & 152.60 & 610.40 & 238.60 & 954.40 & 1.11 \\
\hline RA90 & 0.33 & 122.77 & 370.00 & 0 & 76.30 & 686.70 & 119.30 & 1073.70 & 1.11 \\
\hline RA100 & 0.33 & 122.77 & 370.00 & 0 & 0.00 & 763.00 & 0.00 & 1193.00 & 1.11 \\
\hline W/C29 & 0.29 & 107.30 & 370.00 & 0 & 534.10 & 228.90 & 835.10 & 357.90 & 1.43 \\
\hline W/C31 & 0.31 & 114.70 & 370.00 & 0 & 534.10 & 228.90 & 835.10 & 357.90 & 1.30 \\
\hline W/C33 & 0.35 & 129.50 & 370.00 & 0 & 534.10 & 228.90 & 835.10 & 357.90 & 1.09 \\
\hline W/C35 & 0.37 & 136.90 & 370.00 & 0 & 534.10 & 228.90 & 835.10 & 357.90 & 0.98 \\
\hline SR29 & 0.35 & 129.50 & 370.00 & 0 & 479.22 & 205.38 & 889.98 & 381.42 & 1.09 \\
\hline SR31 & 0.35 & 129.50 & 370.00 & 0 & 506.60 & 217.12 & 862.60 & 369.68 & 1.09 \\
\hline SR35 & 0.35 & 129.50 & 370.00 & 0 & 561.37 & 240.59 & 807.83 & 346.21 & 1.09 \\
\hline SR37 & 0.35 & 129.50 & 370.00 & 0 & 588.76 & 252.32 & 780.44 & 334.48 & 1.09 \\
\hline FA10 & 0.35 & 129.50 & 333.00 & 37 & 534.10 & 228.90 & 835.10 & 357.90 & 1.09 \\
\hline FA20 & 0.35 & 129.50 & 296.00 & 74 & 534.10 & 228.90 & 835.10 & 357.90 & 1.09 \\
\hline FA30 & 0.35 & 129.50 & 259.00 & 111 & 534.10 & 228.90 & 835.10 & 357.90 & 1.09 \\
\hline FA40 & 0.35 & 129.50 & 222.00 & 148 & 534.10 & 228.90 & 835.10 & 357.90 & 1.09 \\
\hline
\end{tabular}

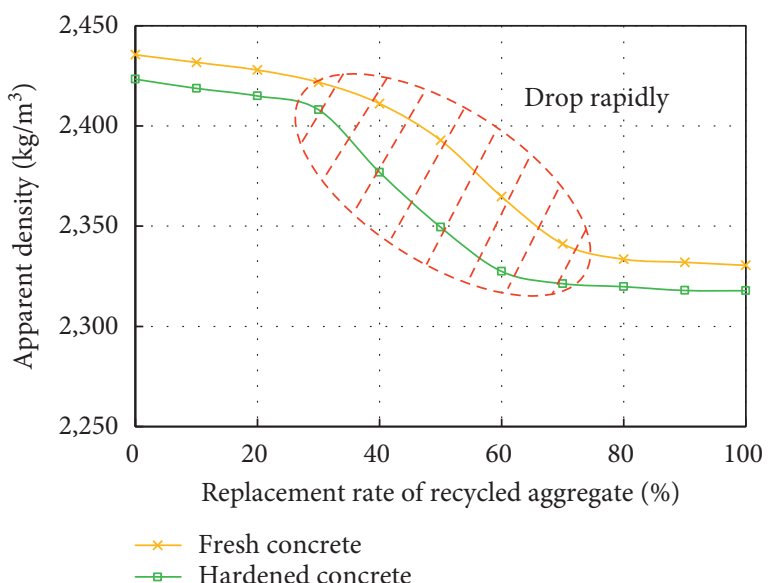

Figure 2: Apparent density of recycled aggregate concrete with different replacement rates.

The compressive strength and flexural tensile strength of recycled concrete with different recycled aggregate replacement rates are shown in Figure 3. Compared with the specimens with $\mathrm{RA}=0$, as the replacement rate of recycled aggregate continues to increase, the compressive strength and flexural tensile strength of recycled concrete decrease. Meanwhile, as the replacement rate increases, the decline is becoming more obvious. It can be seen from the two figures that even if the same mix proportion, the strength of concrete with aggregate made of recycled aggregate is still significantly lower than that of concrete with aggregate made of natural aggregate. However, due to the influence of the water absorption rate of the recycled aggregate, the true water-cement ratio of the specimens with different replacement rates is different, and the strength change is not regular.

A large number of studies have shown that [5], with the increase of recycled aggregate in recycled concrete, the strength of concrete is getting lower and lower. However, there are also data [6] shown that if the old concrete has a higher compressive strength, that is, the strength of the recycled aggregate is higher than the strength of the recycled concrete, the strength of the recycled concrete will increase as the replacement rate of the recycled aggregate increases. There are three reasons for the results of this test. First of all, the strength of recycled aggregate itself is low, resulting in a decrease in the strength of recycled concrete. It can be seen from Table 1 that the crushing value of recycled aggregate is about $32.4 \%$ lower than that of natural aggregate. Therefore, as the amount of recycled aggregate replacing natural aggregate increases, the strength of recycled concrete gradually decreased. Secondly, the water absorption rate of recycled aggregates is relatively large. After the raw material is added with water, the recycled aggregate absorbs water and causes the true water-cement ratio of the cement slurry to decrease. Therefore, as the replacement rate of recycled aggregate increases, the water-cement ratio of cement slurry continues to decrease, and the interfacial bonding between aggregates is further strengthened, resulting in an increase in the strength of recycled concrete. This is similar to the previous conclusion that replaces coarse aggregate only. Thirdly, a certain amount of cement mortar adheres to the surface of the recycled aggregate, and the surface roughness is greater 


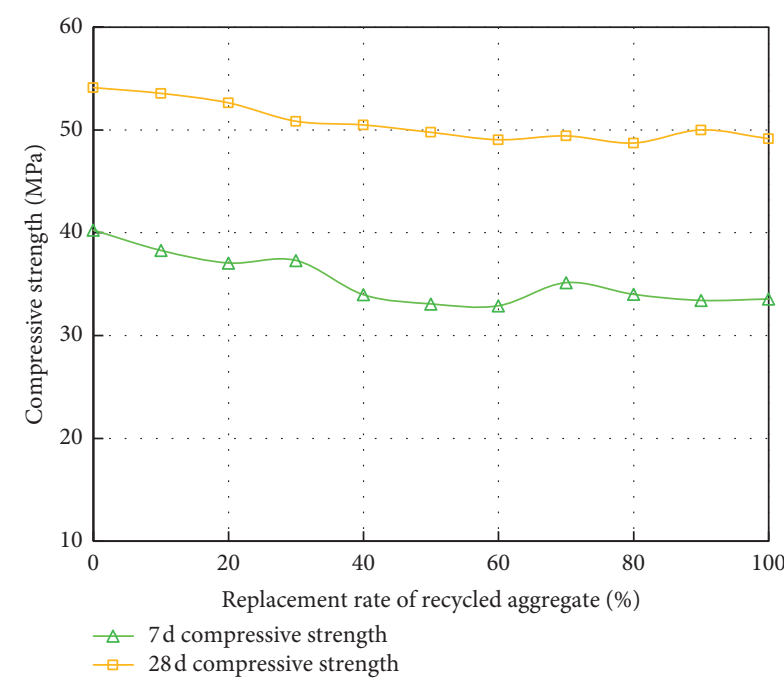

(a)

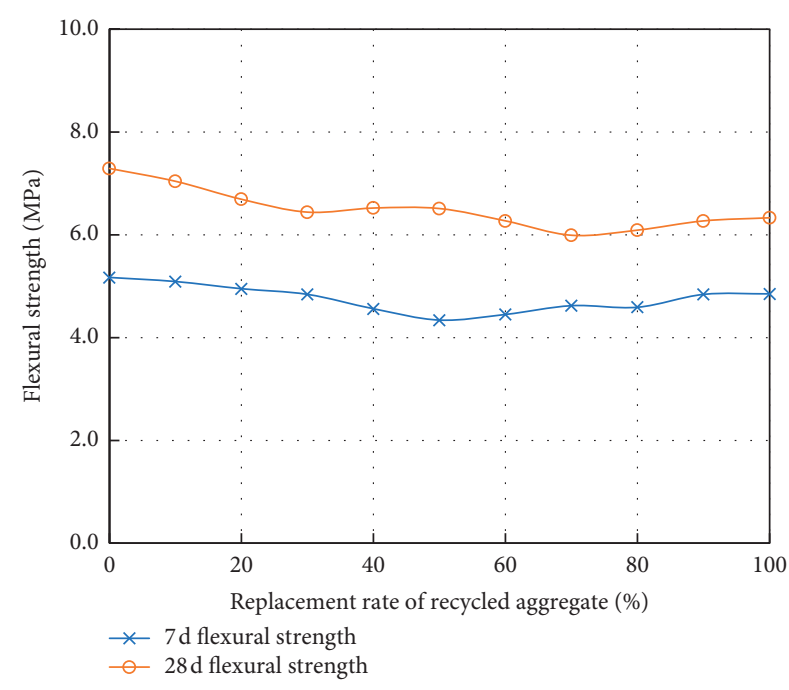

(b)

Figure 3: Strength of recycled aggregate concrete with different replacement rates. (a) The compressive strength. (b) The flexural tensile strength.

than that of natural aggregate. So, the bonding ability with the new hydration product is enhanced, and the strength of the recycled concrete is also increased.

\subsection{Effect of Water-Cement Ratio on Strength of Recycled} Aggregate Concrete. Water-cement ratio is one of the key factors affecting the strength of concrete. In order to study the effect of water-cement ratio on the strength of recycled concrete, five kinds of concrete with water-cement ratio were prepared in the experiment. Among them, the replacement rate of recycled aggregates is $30 \%$. The results of strength at $7 \mathrm{~d}$ and $28 \mathrm{~d}$ tests are shown in Figure 4 . It can be seen from the figures that, with the increase of water-cement ratio, the compressive strength and flexural tensile strength of recycled concrete both showed a downward trend. The water-cement ratio increased from 0.29 to 0.37 , and the $28 \mathrm{~d}$ compressive strength and flexural tensile strength decreased by $17.9 \%$ and $14.7 \%$, respectively. This result is consistent with the general law of the effect of water-cement ratio on concrete strength.

For the compressive strength of recycled concrete, before the water-cement ratio is less than 0.34 , the decrease in compressive strength at $7 \mathrm{~d}$ and $28 \mathrm{~d}$ is greater. After the water-cement ratio is greater than 0.34 , the decrease is significantly weakened. For the flexural tensile strength, there is also a turning point similar to the change law of compressive strength. After the water-cement ratio is greater than 0.32 , the decrease in the flexural tensile strength at $28 \mathrm{~d}$ of recycled concrete is significantly weakened. The main reason for this phenomenon is that the recycled aggregate has water absorption. When the water-cement ratio is relatively small, the water is mainly absorbed by the cement and the surface of the aggregate and recycled aggregates cannot fully absorb water. As the water-cement ratio increases, a large amount of free water appears in the mixture, and this part of water is gradually absorbed by the recycled aggregate. This actually reduces the effective water-cement ratio of the recycled concrete, resulting in a decrease in the strength reduction.

\subsection{Effect of Sand Ratio on Strength of Recycled Aggregate} Concrete. Sand ratio has a greater impact on the workability of concrete, which in turn affects the strength of concrete. The test used a water-cement ratio of 0.35 and a recycled aggregate replacement rate of $30 \%$ to prepare recycled concrete that with 5 kinds of sand ratio. The effect of sand ratio on compressive strength and flexural tensile strength was measured. The results are shown in Figure 5. As the sand ratio increases, the strength of recycled concrete shows a trend of increasing first and then decreasing. This is true regardless of compressive strength or flexural tensile strength. This is similar to the effect of sand ratio on the strength of conventional concrete. The reason is that as the sand ratio increases, the concrete becomes denser. However, too high a sand ratio will destroy the skeleton structure of the aggregate, resulting in a drop in concrete strength.

It can be seen from the figure that the compressive strength at $28 \mathrm{~d}$, the flexural tensile strength at $7 \mathrm{~d}$, and the flexural tensile strength at $28 \mathrm{~d}$ of recycled concrete reach maximum values when the sand ratio is $39 \%$. Therefore, recycled concrete has the same optimum sand ratio as conventional concrete. Using this sand ratio, recycled concrete can obtain maximum compressive strength and flexural tensile strength. Through a large number of experiments, when the replacement rate of recycled aggregate is $30 \%$, the optimal sand ratio of recycled concrete is $38 \%-39 \%$. As the replacement rate of recycled aggregates increases, the optimal sand ratio decreases. The sand ratio is controlled between $32 \%$ and $38 \%$, which is ideal for recycled concrete. 


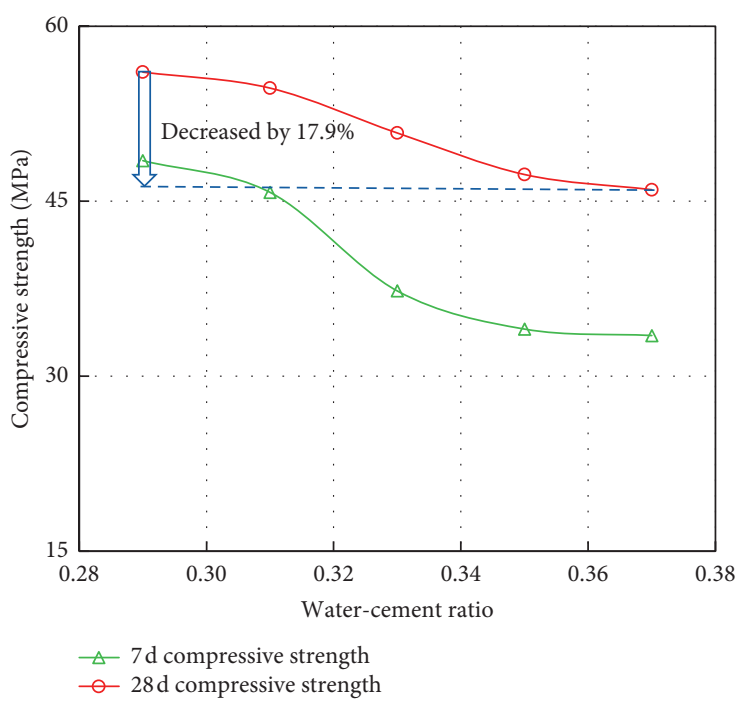

(a)

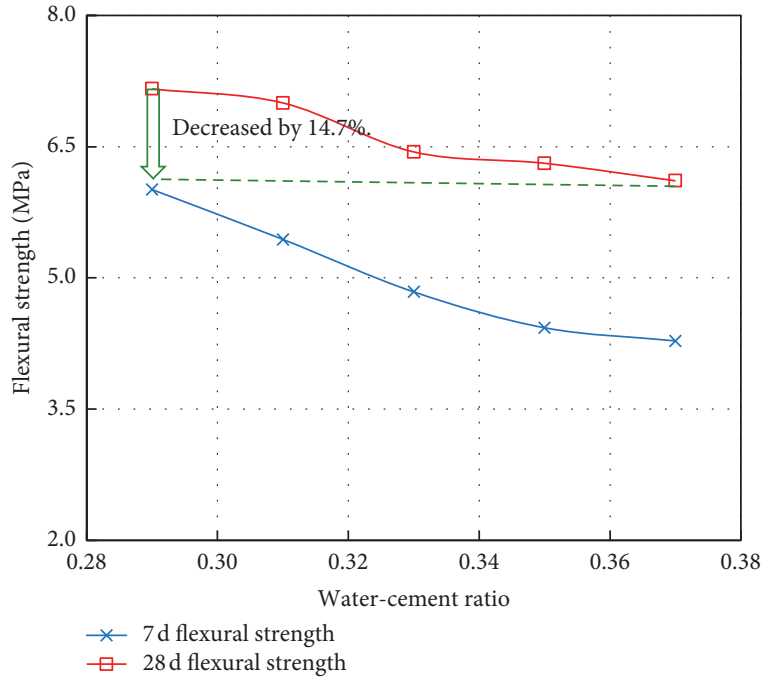

(b)

Figure 4: Strength of recycled aggregate concrete with different water-cement ratios. (a) The compressive strength. (b) The flexural tensile strength.

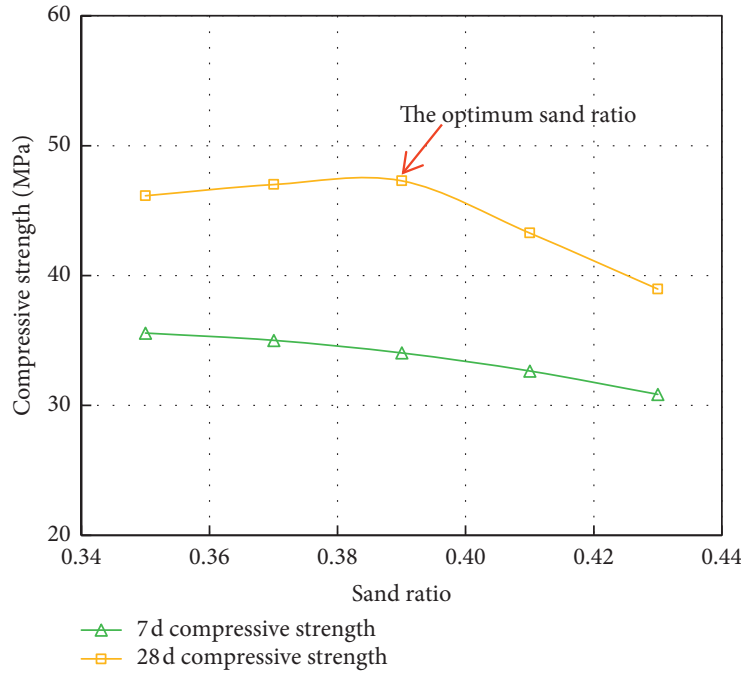

(a)

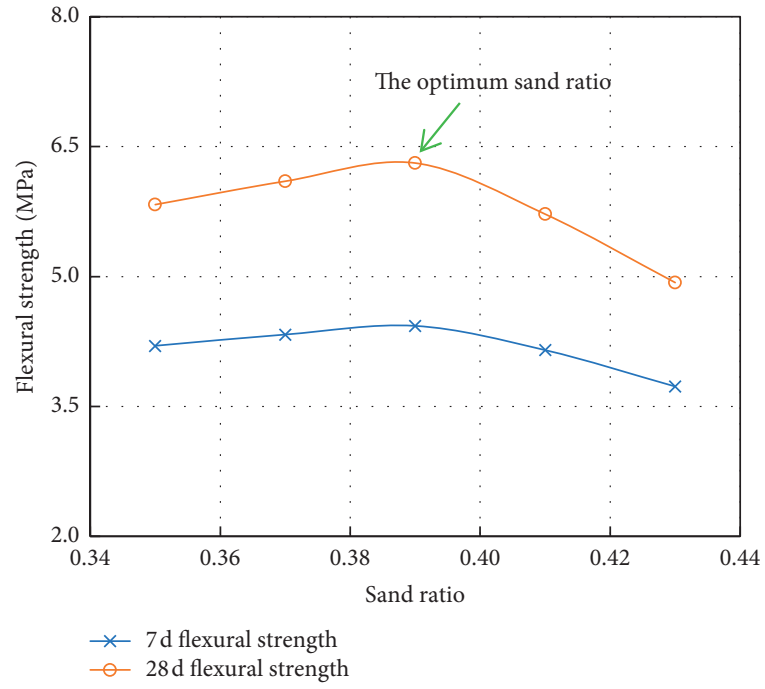

(b)

FiguRE 5: Strength of recycled aggregate concrete with different sand ratios. (a) The compressive strength. (b) The flexural tensile strength.

3.4. Effect of Fly Ash on Strength of Recycled Aggregate Concrete. Adding fly ash to concrete can improve the workability, compactness, and durability of concrete. Several groups of recycled concrete specimens with different contents of fly ash were prepared in the experiment. The water-cement ratio of these specimens is 0.35 , and the replacement rate of recycled aggregates is $30 \%$. Then, the effect of the fly ash content on the compressive strength and flexural tensile strength was measured. The results are shown in Figure 6. With the increase of fly ash content, the strength of recycled concrete at $7 \mathrm{~d}$ has decreased to some extent, but the strength at $28 \mathrm{~d}$ has been slightly improved. This is similar to the effect of fly ash content on the strength of conventional concrete [7]. There are two main reasons for this result: on the one hand, fly ash has a volcanic ash effect, but the effect is not obvious in the first $7 \mathrm{~d}$; on the other hand, the addition of fly ash improves the density of concrete, making $28 \mathrm{~d}$ strength has been greatly improved.

However, for recycled concrete, the more fly ash is not the better even for $28 \mathrm{~d}$ strength. It can be seen from the figure that, during the increase of the fly ash content from 0 to $30 \%$, the compressive strength and flexural tensile strength at $28 \mathrm{~d}$ increased by $16 \%$ and $4.9 \%$, respectively. However, when the fly ash content increased to $40 \%$, the $28 \mathrm{~d}$ compressive strength and flexural tensile strength decreased to varying degrees. For compressive strength and flexural 


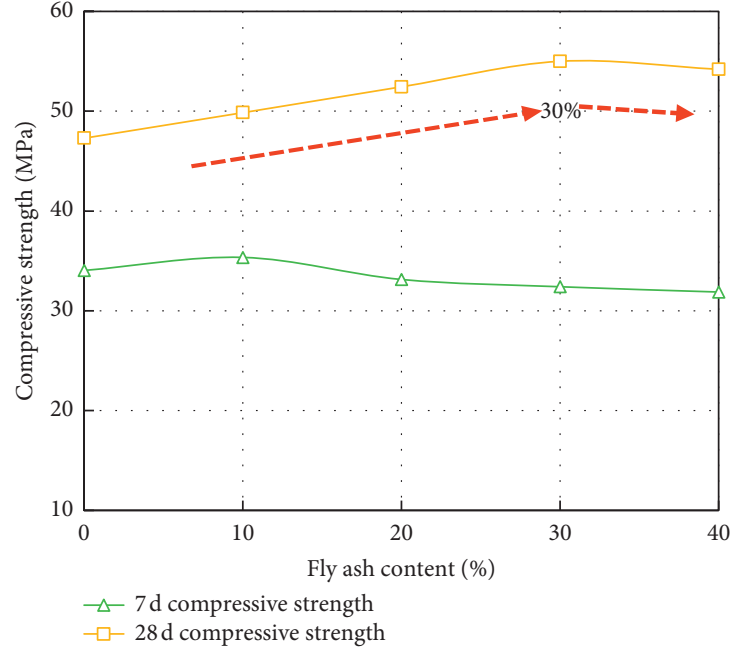

(a)

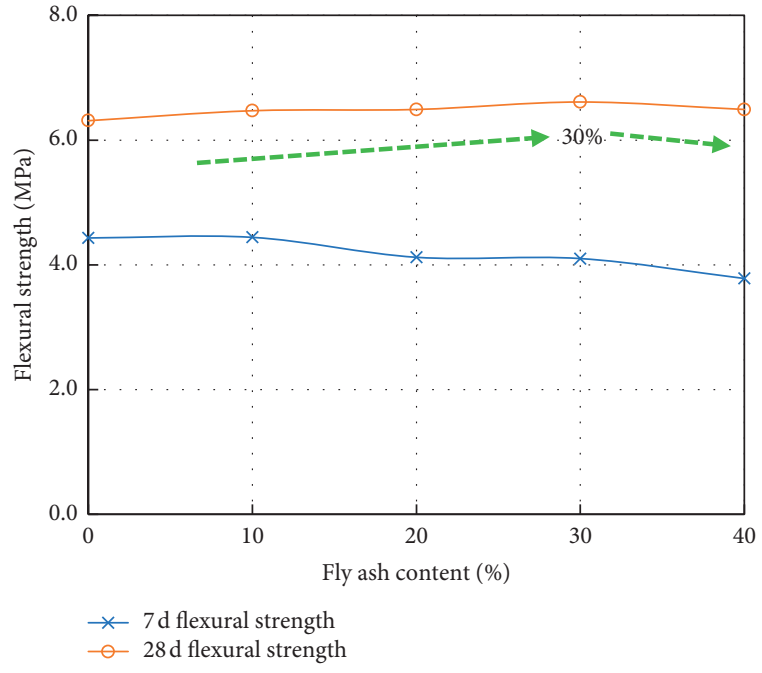

(b)

FIGURE 6: Strength of recycled aggregate concrete with different fly ash contents. (a) The compressive strength. (b) The flexural tensile strength.

tensile strength, the optimal content of fly ash is different. Therefore, for recycled concrete, the content of fly ash should be determined according to the compressive or flexural needs of the structure and the changes in compressive strength and flexural tensile strength.

\section{Conclusion}

(1) The effect of recycled aggregates on the strength of recycled concrete is related to the strength of recycled aggregates, the strength of natural aggregates, and the strength of old concrete. As the replacement rate of recycled aggregates increases, the strength of recycled concrete may increase or decrease.

(2) The strength of recycled concrete decreases with increasing water-cement ratio. However, due to the water absorption of the recycled aggregate, it has a certain inhibitory effect on the strength reduction. The greater the content of recycled aggregates, the more obvious the inhibition effect of the strength reduction of recycled concrete.

(3) Recycled concrete has the optimum sand ratio as conventional concrete. When the replacement rate of recycled aggregate is $30 \%$, the optimal sand ratio of recycled concrete is $38 \%-39 \%$. As the replacement rate of recycled aggregates increases, the optimal sand ratio decreases. The sand ratio is controlled between $32 \%$ and $38 \%$, which is ideal for recycled concrete.

(4) With the increase of fly ash content, the strength of recycled concrete at $7 \mathrm{~d}$ has decreased to some extent, but the strength at $28 \mathrm{~d}$ has been slightly improved. In addition, for compressive strength and flexural tensile strength, the optimal content of fly ash is different.

\section{Data Availability}

The data used to support the findings of this study are available from the corresponding author upon request.

\section{Conflicts of Interest}

The authors declare that there are no conflicts of interest regarding the publication of this paper.

\section{Acknowledgments}

This work was supported by the National Natural Science Foundation of China (no. 51808329) and Science and Technology Project of Shanxi Transportation Holding Group Co., Ltd. (nos. 19-JKKJ-6 and 19-JKKJ-67).

\section{References}

[1] K. Verian, "Using recycled concrete as coarse aggregate in pavement concrete," MS Thesis, Purdue University, West Lafayette, IN ,USA, 2012.

[2] N. D. Oikonomou, "Recycled concrete aggregates," Cement and Concrete Composites, vol. 27, no. 2, pp. 315-318, 2005.

[3] A. V. Acker, "Recycling of concrete at a precast concrete plant," in Proceedings of the Sustainable Construction: Use of Recycled Concrete Aggregate, pp. 321-332, London, UK, November 1998.

[4] L. Wang and C. Li, "Research progress on the development and utilization of fly ash resources technology," Mineral Protection and Utilization, vol. 39, no. 4, pp. 38-45, 2019.

[5] T. Liu, Y. Zhang, M. Xu et al., "Research on the calculation of $\mathrm{CO}_{2}$ emission of raw material carbonate decomposition in cement enterprises," China Cement, vol. 26, no. 2, pp. 77-80, 2019.

[6] M. S. Rahman and S. I. Ahmad, "Strength properties of concrete made from recycled brick concrete and EAF slag blended as coarse aggregate," Materials Science Forum, vol. 984, pp. 207-212, 2020. 
[7] J. Xiao, J. Li, and Y. Lan, "The latest progress and comments on the research of recycled concrete technology," Concrete, vol. 10, pp. 17-20+57, 2003.

[8] D. Yang, Y. Hao, and T. Wang, "Experimental research on recycled aggregate concrete for highway pavement," in Proceedings of the ICCTP 2010, Beijing, China, August 2010.

[9] Y. Hou, X. Ji, X. Su, W. Zhang, and L. Liu, "Laboratory investigations of activated recycled concrete aggregate for asphalt treated base," Construction and Building Materials, vol. 65 , pp. 535-542, 2014.

[10] J. Qiu, D. Q. S. Tng, and E.-H. Yang, "Surface treatment of recycled concrete aggregates through microbial carbonate precipitation," Construction and Building Materials, vol. 57, pp. 144-150, 2014.

[11] C. Shi, Y. Li, J. Zhang, W. Li, L. Chong, and Z. Xie, "Performance enhancement of recycled concrete aggregate - a review," Journal of Cleaner Production, vol. 112, pp. 466-472, 2016.

[12] Y. Hou, X. Ji, and X. Su, "Mechanical properties and strength criteria of cement-stabilised recycled concrete aggregate," International Journal of Pavement Engineering, vol. 20, no. 3, pp. 339-348, 2019.

[13] C. S. Poon and D. Chan, "Feasible use of recycled concrete aggregates and crushed clay brick as unbound road subbase," Construction and Building Materials, vol. 20, no. 8, pp. 578-585, 2006.

[14] I. Vegas, J. A. Ibañez, A. Lisbona, A. Sáez de Cortazar, and M. Frías, "Pre-normative research on the use of mixed recycled aggregates in unbound road sections," Construction and Building Materials, vol. 25, no. 5, pp. 2674-2682, 2011.

[15] M. Diagne, J. M. Tinjum, and K. Nokkaew, "The effects of recycled clay brick content on the engineering properties, weathering durability, and resilient modulus of recycled concrete aggregate," Transportation Geotechnics, vol. 3, pp. 15-23, 2015.

[16] A. Arul, J. Piratheepan, Y. Ali et al., "Geotechnical properties of recycled concrete aggregate in pavement sub-base applications," Geotechnical Testing Journal, vol. 35, no. 5, pp. 1-9, 2012.

[17] M. M. Disfani, A. Arulrajah, H. Haghighi, A. Mohammadinia, and S. Horpibulsuk, "Flexural beam fatigue strength evaluation of crushed brick as a supplementary material in cement stabilized recycled concrete aggregates," Construction and Building Materials, vol. 68, pp. 667-676, 2014.

[18] M. Alireza, A. Arul, S. Jay et al., "Laboratory evaluation of the use of cement-treated construction and demolition materials in pavement base and subbase applications," Journal of Materials in Civil Engineering, vol. 27, no. 6, pp. 1-12, 2015.

[19] B. Huang and X. Pi, Building Materials, China Construction Industry Press, Beijing, China, 1995.

[20] T. C. Hansen and H. Narud, "Strength of recycled concrete made from crushed concrete coarse aggregate," Concrete International, vol. 5, no. 1, pp. 79-83, 1983.

[21] J. Shen and Y. Zhang, "Fiber-reinforced mechanism and mechanical performance of composite fibers reinforced concrete," Journal of Wuhan University of Technology-Mater. Sci. Ed., vol. 35, no. 1, pp. 121-130, 2020.

[22] S. Zhang, "Water absorption and water return characteristics of recycled aggregate and its effect on concrete shrinkage," $\mathrm{PhD}$ Thesis, Beijing Architecture University, Beijing, China, 2019. 